\title{
Torque Ripple Minimization in Direct Torque Control of Brushless DC Motor
}

\begin{abstract}
Zhenguo Li ${ }^{\dagger}$, Songfa Zhang*, Shenghai Zhou** and Jin-Woo Ahn***
Abstract - This paper mainly proposes a direct torque control strategy to minimize torque ripple in brushless DC (BLDC) motor. BLDC motor has large current and torque ripple when one voltage vector applied in one cycle due to its low inductance. Hence, this paper proposed a hysteresis torque control with PWM mode to control the resultant torque. Moreover, when the direct torque control system is operating during the two-phase half-bridge $120^{\circ}$ conduction mode, large torque ripple in commutation area appears every 120 electrical degree. Based on analyzing the root of torque ripple in detail, lookup tables of switching devices states for new half-bridge modulation mode in the positive and negative reference torque put forwarded. Finally, simulations by MATLAB software and experiment results from DSP are presented to verify the feasibility and effectiveness of the proposed strategy operating in four-quadrant operation.
\end{abstract}

Keywords: Brushless DC Motor (BLDCM), Direct Torque Control (DTC), Torque ripple minimization, Four-quadrant operation

\section{Introduction}

Due to simple structure, high power density, large torqueto-current ratio, high efficiency and good controllability over a wide range of speed, brushless DC Motor (BLDCM) is widely used in industrial and vehicle fields [1]. However, obvious torque ripple is caused by the non-ideal trapezoidal wave back EMF, non-ideal square current waveform, the cogging torque and air gap magnetic field distortion generated by armature reaction. Hence, the torque ripple minimization is highly interested by researchers in recent years.

Due to robustness against parameter uncertainty and ability to control the electromagnetic torque directly, direct torque control (DTC) method has been considered dramatically among various torque ripple minimization methods ${ }^{[2-9]}$. Traditional DTC method used in AC motor is applied to BLDCM [2-4], which adopted dual closed loop of torque and stator flux linkage. Among these references, switch table is applied to two-phase full bridge $120^{\circ}$ mode and output torque is calculated by derivative of rotor flux linkage and stator current [2]. However, due to adopt two phase full bridge $120^{\circ}$ mode, turn-off phase voltage cannot be calculated by bus voltage and switch state. Therefore, it is required to calculate extra computation to estimate the

$\dagger$ Corresponding Author: School of Electrical Engineering, Yanshan University, China. (lzg@ysu.edu.cn)

* Gree Electric Appliances, Inc, of Zhuhai, China. (songfazhang@ 163.com)

** State Grid Jibei Electric Power CO., LTD. Maintenance Branch., China. (a117410628@163.com)

*** Dept. of Mechatronics Engineering, Kyungsung University, Korea (jwahn@ks.ac.kr)

Received: January 16, 2013; Accepted: March 13, 2014 turn-off phase voltage. Based on [2], minimizing torque ripple during commutation is discussed by [3], which combined two-phase and three-phase modes. However, only three-phase mode is applied, and indirect stator flux linkage loop is substituted for stator current loop of $d$ axis component [4].

Direct-Self Control (DSC) in AC motor is applied to BLDCM directly in [5]. In this method, 3D space is defined with conduction phase on X-Y plane and nonconduction phase on $\mathrm{Z}$ plane. Trivector stator voltage and flux become simple hexagon after projected onto X-Y plane, and the problem of BLDCM stator reference flux periodic change with stator position is solved. In [6], hysteresis torque control output and stator pole position decide the suitable voltage vector, and switch table is applied to two-phase full bridge $120^{\circ}$ mode without fluxloop. Compared with reference torque, output torque is calculated by instantaneous voltage and current [7]. Reference voltage is calculated by mathematical model, and this method realized by PWM control mode.

This paper proposes a DTC method for BLDCM to minimize torque ripple. In conventional DTC method, usually one voltage vector and low inductance in one cycle are adopted, which results in large phase current and torque ripple. Hence, motor torque is controlled by combined mode of hysteresis torque control and PWM mode in this paper. In addition, when the DTC system operating in the two-phase half bridge $120^{\circ}$ conduction mode, large torque ripple in commutation appears at every 120 electrical degree, thus on the basis of analyzing the root of torque ripple in detail, proposed method puts forward the lookup table of switching devices states of new half-bridge modulation mode in the positive and negative reference 
torque. Finally, simulation and experiment results are presented to verify the feasibility and effectiveness of the proposed strategy operating in four-quadrant operation.

\section{Direct Torque Control System of BLDCM}

\subsection{Conventional direct torque control technology}

The power converter for BLDCM usually adopts voltage source inverter as shown in Fig. 1.

Conventional direct torque control technology for BLDCM can be divided into two types based on considering flux-linkage control loop or not. In direct torque control with flux-linkage control loop, exact value of voltage at turn-off angle is uncertain and it may caused to make problem for stator reference flux due to its periodic change with stator position. Hence, direct torque control without flux-linkage control loop considered in this paper. Fig. 2 and Table 1 show the structural diagram and lookup table of switching devices. In the table, 1 represents turn-on; 0 deputes turn-off, and six digital corresponds to the upper and lower switch states in $a, b, c$ phase, respectively. Considering different switching losses of full-bridge, halfbridge mode and BLDCM PWM control mode, this table selects the equivalent switching devices based on half-

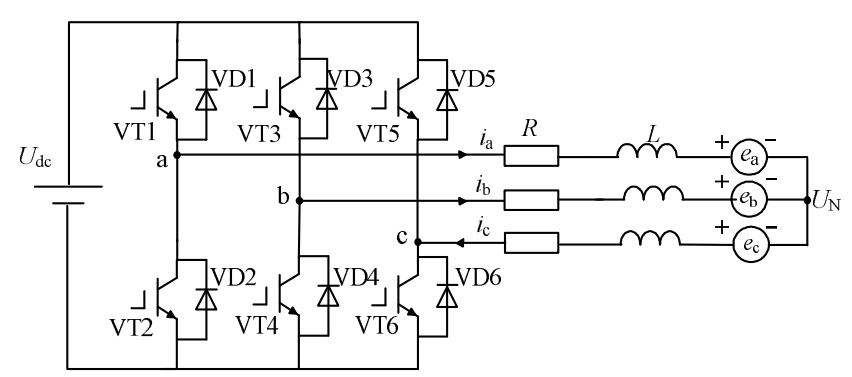

Fig. 1. Voltage source inverter and BLDCM equivalent circuit

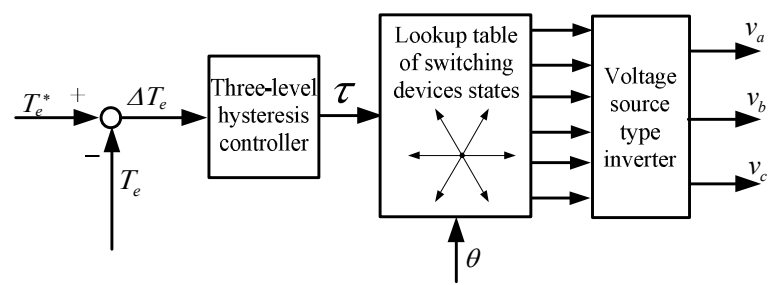

Fig. 2. Block diagram of DTC with Hysteresis control mode

Table 1. Lookup table of switching devices states with Hysteresis control mode

\begin{tabular}{c|c|c|c|c|c|c}
\hline$\tau$ & $\begin{array}{c}\text { Sector } \\
\text { I }\end{array}$ & $\begin{array}{c}\text { Sector } \\
\text { II }\end{array}$ & $\begin{array}{c}\text { Sector } \\
\text { II }\end{array}$ & $\begin{array}{c}\text { Sector } \\
\text { IV }\end{array}$ & $\begin{array}{c}\text { Sector } \\
\text { V }\end{array}$ & $\begin{array}{c}\text { Sector } \\
\text { VI }\end{array}$ \\
\hline 1 & 100100 & 100001 & 001001 & 011000 & 010010 & 000110 \\
\hline 0 & 000100 & 000001 & 000001 & 010000 & 010000 & 000100 \\
\hline-1 & 000000 & 000000 & 000000 & 000000 & 000000 & 000000 \\
\hline
\end{tabular}

bridge H_PWM-L_ON method.

\subsection{Direct torque control technology with hysteresis and PWM mode}

Due to small value of inductance in brushless DC motor, when one voltage vector is applied in one cycle, large current and torque ripple would be resulted. This will reduces the accuracy of the torque control as well. Although, decreasing torque control cycle may reduces torque ripple, however, other problems may come arise such as increasing the cost of hardware and running time of program. In this paper, direct torque control method using hysteresis and PWM mode is selected as shown in Fig. 3. A four-level hysteresis controller is applied to improve the dynamic performance of torque control. The torque deviation $\Delta T_{e}$ is compared with four threshold values $\left( \pm T_{t h 1}, \pm T_{t h 2}\right)$ to get one of the four levels ( $\pm D_{1 \text { min }}$, $\left.\pm D_{1 \max }\right) . D_{2}$ corresponds to line-EMF in two-phase $120^{\circ}$ conduction mode, which is approximatly proportional to speed. Table 2 shows lookup table of switching devices states under the direct torque control. In this table, $D$ represents upper switching device conducting PWM mode with $D$ times duty cycle, $-D$ represents lower switching device conducting PWM mode with $(1-D)$ times duty cycle, 1 indicates upper switch conduction, -1 is considered for lower switch conduction, 0 represents upper and lower switchs in turn-off mode.

\subsection{Commutation torque ripple analysis and torque ripple minimization}

Neglecting phase resistance voltage drop, when sector I changes to sector II, that is $A+B-$ conduction state will change to $\mathrm{A}+\mathrm{C}-$ conduction mode. Before entering the sector II from Table 2, terminal voltages of $a$ and $b$ phases are $D U_{d c}, 0$ respectively, and the ideal back EMFs of $a$, $b, c$ phases are $E,-E,-E$, respectively. Therefore, the

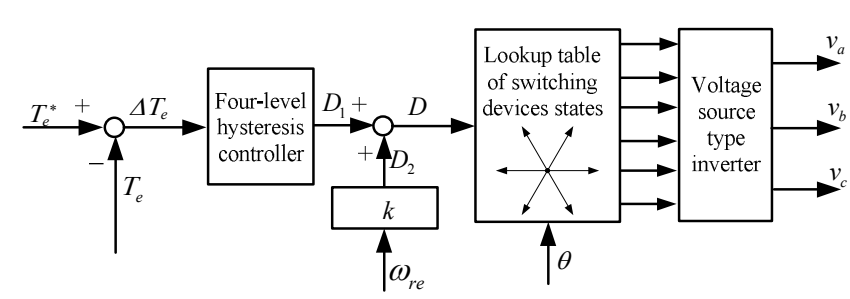

Fig. 3. Block diagram of DTC with Hysteresis control and PWM mode

Table 2. Lookup table of switching devices states with Hysteresis control and PWM mode

\begin{tabular}{c|c|c|c|c|c|c}
\hline & $\begin{array}{c}\text { Sector } \\
\text { I }\end{array}$ & $\begin{array}{c}\text { Sector } \\
\text { II }\end{array}$ & $\begin{array}{c}\text { Sector } \\
\text { III }\end{array}$ & $\begin{array}{c}\text { Sector } \\
\text { IV }\end{array}$ & $\begin{array}{c}\text { Sector } \\
\text { V }\end{array}$ & $\begin{array}{c}\text { Sector } \\
\text { VI }\end{array}$ \\
\hline$D \geq 0$ & $\mathrm{D},-1,0$ & $\mathrm{D}, 0,-1$ & $0, \mathrm{D},-1$ & $-1, \mathrm{D}, 0$ & $-1,0, \mathrm{D}$ & $0,-1, \mathrm{D}$ \\
\hline$D<0$ & $0,-\mathrm{D}, 0$ & $0,0,-\mathrm{D}$ & $0,0,-\mathrm{D}$ & $-\mathrm{D}, 0,0$ & $-\mathrm{D}, 0,0$ & $0,-\mathrm{D}, 0$ \\
\hline
\end{tabular}


changing rate of a phase current can be presented as follows:

$$
\frac{d i_{a}}{d t}=\frac{D}{2 L} U_{d c}-\frac{1}{L} E
$$

where, $E$ is the peak value of ideal back EMF.

It can be seen that the changing rate of a phase current is 0 , and the value of $D$ in this time is as follows.

$$
D=\frac{2 E}{U_{d c}}
$$

Similarly, after entering the sector II, considering that $\mathrm{b}$ phase current still exists during commutation, it can be obtained from Table 2 that the terminal voltages of $a, b, c$ phases are $U_{d c}, U_{d c}, 0$, respectively, and the changing rate of a phase current can be represented as follows,

$$
\frac{d i_{a}}{d t}=\frac{2 D-1}{3 L} U_{d c}-\frac{4}{3 L} E
$$

the value of $D$ is calculated from the following equation:

$$
D=\frac{1}{2}+\frac{2 E}{U_{d c}}
$$

Comparing (2) and (4) during commutation, when $E<U_{d c} / 4$, i.e., at low speed, the value of $D$ need to increase $1 / 2$ suddenly to ensure constant output torque, and When $E>U_{d c} / 4$, i.e., at high speed, required value of $D$ is greater than 1 , apparently the torque ripple is unavoidable.

With the same explanations, before and after entering the sector III, the values of $D$ can be achieved by Eqs. (2) and (5), respectively.

$$
D=\frac{4 E}{U_{d c}}
$$

During entering the sector $\mathrm{III}$, when $E<U_{d c} / 4$, i.e., at low speed, the value of $D$ need to increase $2 E / U_{d c}$ to ensure constant output torque and it is less than $1 / 2$. In this situation current and torque ripple would be less than commutation in sector II, so that the lower speed, the larger difference.

From above analysis, it can be seen that when the motor operates at low speed based on the rules mentioned by Table 2, large torque ripple in commutation appears every 120 electrical degree.

In order to solve the above problems, new lookup table is introduced which is shown by Table 3 . This table still applied in two-phase half-bridge 120 conduction mode, including all switching status under the positive and negative reference torque. Moreover, the table devides
60 electrical degree in one sector into two 30 electrical degree with different PWM mode and same value of $D$. Thus it cannot produce the current and the torque ripple.

At the next step, torque ripple in low speed based on the value of $D$ before and after entering sector II is analyzed. At the istant before entering sector II, terminal voltages of $a$ and $b$ phases are $U_{d c},(1-D) U_{d c}$, respectively, and the ideal back EMFs of $a, b, c$ phases are $E,-E,-E$, respectively. Thereby, the value of $D$ in this moment can be calculated from Eq. (2). Similarly, in the commutation area in sector II, as shown in Table 3 , terminal voltages of $a, b, c$ phases are $U_{d c}, U_{d c},(1-D) U_{d c}$, respectively, the changing rate of a phase current can be represented as follows.

$$
\frac{d i_{a}}{d t}=\frac{D}{3 L} U_{d c}-\frac{4}{3 L} E
$$

The changing rate of a phase current is 0 in the ideal situation, then the value of $D$ can be calculated, similar to Eq. (5). Compared with method in 2.4 , the value of $D$ doesn't require to increase $1 / 2$ to solve the problem in which large torque ripple in commutation appears every 120 electrical degree. The value of $D$ in other commutation region can be obationed in the same way, and the results are same.

\subsection{The switching states analysis and requirements in the transition of positive and negative rotation}

For the system operating in four-quadrant operation, the reference torque should be varying between positive and negative direction. At this moment, only using lookup table introduced by Table 3 can result in the upper and lower switching devices conduction at the same time. For example, in the sector $\mathrm{I}\left(0^{\circ} \sim 30^{\circ}\right)$, if the reference torque

\begin{tabular}{|c|c|c|c|c|c|}
\hline & & \multicolumn{2}{|c|}{$T_{e}^{*} \geq 0$} & \multicolumn{2}{|c|}{$T_{e}^{*}<0$} \\
\hline Sector & Electrical angle & $D \geq 0$ & $D<0$ & $D \geq 0$ & $D<0$ \\
\hline \multirow{2}{*}{$\begin{array}{c}\text { Sector } \mathrm{I} \\
\mathrm{AB}\end{array}$} & Front $30^{\circ}$ & $\mathrm{D},-1,0$ & $\mathrm{D}, 0,0$ & $-\mathrm{D}, 0,0$ & $-\mathrm{D}, 1,0$ \\
\hline & Behind $30^{\circ}$ & $1,-\mathrm{D}, 0$ & $0,-\mathrm{D}, 0$ & $0, \mathrm{D}, 0$ & $-1, \mathrm{D}, 0$ \\
\hline \multirow{2}{*}{$\begin{array}{c}\text { Sector II } \\
\text { AC }\end{array}$} & Front $30^{\circ}$ & $1,0,-\mathrm{D}$ & $0,0,-\mathrm{D}$ & $0,0, \mathrm{D}$ & $-1,0, \mathrm{D}$ \\
\hline & Behind $30^{\circ}$ & $\mathrm{D}, 0,-1$ & $\mathrm{D}, 0,0$ & $-\mathrm{D}, 0,0$ & $-\mathrm{D}, 0,1$ \\
\hline \multirow{2}{*}{$\begin{array}{c}\text { Sector III } \\
\text { BC }\end{array}$} & Front $30^{\circ}$ & $0, \mathrm{D},-1$ & $0, \mathrm{D}, 0$ & $0,-\mathrm{D}, 0$ & $0,-\mathrm{D}, 1$ \\
\hline & Behind $30^{\circ}$ & $0,1,-\mathrm{D}$ & $0,0,-\mathrm{D}$ & $0,0, \mathrm{D}$ & $0,-1, \mathrm{D}$ \\
\hline \multirow{2}{*}{$\begin{array}{c}\text { Sector IV } \\
\text { BA }\end{array}$} & Front $30^{\circ}$ & $-\mathrm{D}, 1,0$ & $-\mathrm{D}, 0,0$ & $\mathrm{D}, 0,0$ & $\mathrm{D},-1,0$ \\
\hline & Behind $30^{\circ}$ & $-1, \mathrm{D}, 0$ & $0, \mathrm{D}, 0$ & $0,-\mathrm{D}, 0$ & $1,-\mathrm{D}, 0$ \\
\hline \multirow{2}{*}{$\begin{array}{r}\text { Sector } V \\
\mathrm{CA}\end{array}$} & Front $30^{\circ}$ & $-1,0, \mathrm{D}$ & $0,0, \mathrm{D}$ & $0,0,-\mathrm{D}$ & $1,0,-\mathrm{D}$ \\
\hline & Behind $30^{\circ}$ & $-\mathrm{D}, 0,1$ & $-\mathrm{D}, 0,0$ & $\mathrm{D}, 0,0$ & $\mathrm{D}, 0,-1$ \\
\hline \multirow{2}{*}{$\begin{array}{c}\text { Sector VI } \\
\text { CB }\end{array}$} & front $30^{\circ}$ & $0,-\mathrm{D}, 1$ & $0,-\mathrm{D}, 0$ & $0, \mathrm{D}, 0$ & $0, \mathrm{D},-1$ \\
\hline & Behind $30^{\circ}$ & $0,-1, \mathrm{D}$ & $0,0, \mathrm{D}$ & $0,0,-\mathrm{D}$ & $0,1,-\mathrm{D}$ \\
\hline
\end{tabular}
becomes reverse, the upper and lower switching device of a phase will conduct all the time. To solve this problem, add a whole turn-off state $(0,0,0)$ in this particular case. It not

Table 3. Lookup table of switching devices states with consider commutation torque ripple 


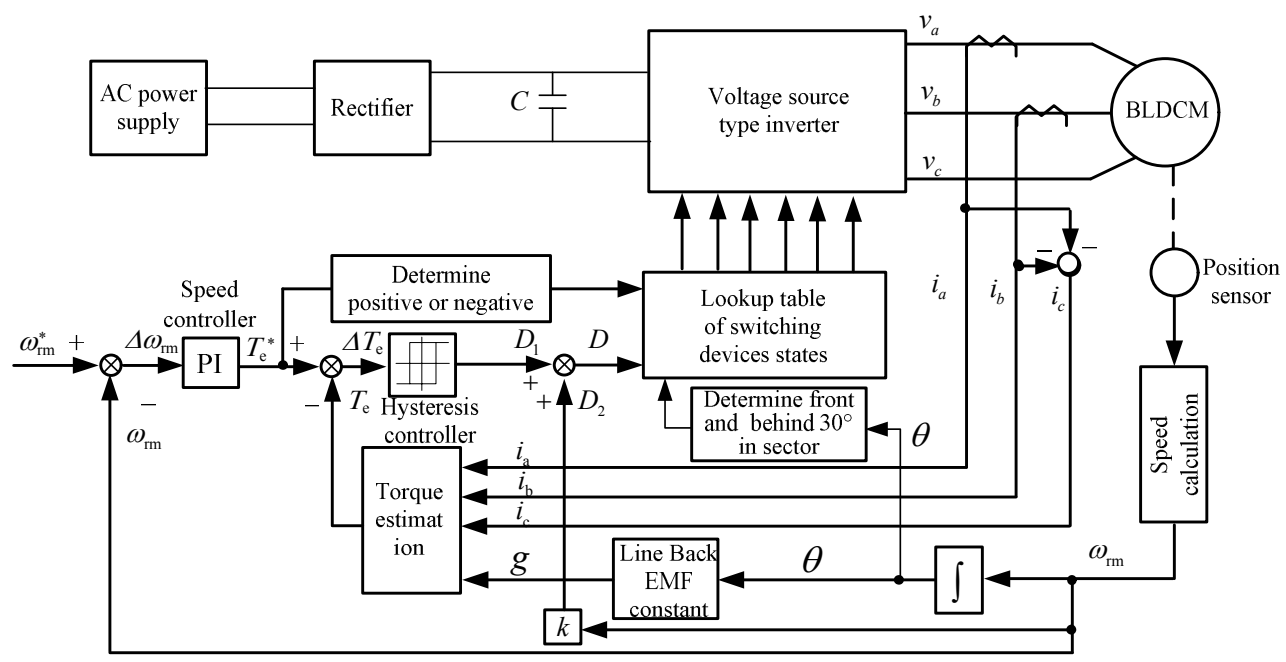

Fig. 4. Structural diagram of direct torque control system

only avoid bridge arm to become short circuit, but also accelerate the transition process.

In order to analyse the transition process in sector I, when reference torque changes from positive to negative a and $\mathrm{b}$ phases are in conducting states. When suddenly adding $(0,0,0)$ state, the motor current direction unchangs at that instant, so terminal voltages of $a$ and $b$ phase are 0 , $D U_{d c}$, respectively, then the change rate of $a$ and $b$ phases current in this torque control cycle are presented as follows, respectively.

$$
\begin{aligned}
& \frac{d i_{a}}{d t}=-\frac{1}{2 L} U_{d c}-\frac{1}{L} E \\
& \frac{d i_{b}}{d t}=\frac{1}{2 L} U_{d c}+\frac{1}{L} E
\end{aligned}
$$

It can be seen that current quickly drop or rise to 0 .

\subsection{System structure}

Fig. 4 shows the proposed BLDCM DTC system, with DTC as the inner loop and PI speed control as the outer loop and can be applied for operating in four-quadrant. Control system consists mainly of voltage source inverter, lookup table of switching devices states, position detection and speed calculation, electromagnetic torque estimation, PI speed controller and hysteresis torque controller.

In the introduced system, the output torque can be calculated by the line EMF coefficient depending on rotor position and phase current. Considering sector I for an instance, the output torque can be calculated as follows

$$
T_{e}=\frac{e_{a c} i_{a}+e_{b c} i_{b}}{\omega_{r m}}
$$

where $e_{a c}$ is line back-EMF between widings $a$ and $c$, others are similar.
The line back EMF $e_{a c}, e_{b c}, e_{b a}, e_{c a}, e_{c b}, e_{a b}$ are symmetrical and proportional to rotor mechanical speed, as follows,

$$
\begin{aligned}
e_{a c}(\theta) & =e_{b c}\left(\theta-\frac{1}{3} \pi\right)=e_{b a}\left(\theta-\frac{2}{3} \pi\right)=e_{c a}(\theta-\pi) \\
& =e_{c b}\left(\theta-\frac{4}{3} \pi\right)=e_{a b}\left(\theta-\frac{5}{3} \pi\right)=g(\theta) \cdot \omega_{r m}
\end{aligned}
$$

where, $g(\theta)$ is the line back-EMF constant based on line voltage between $a$ and $c$.

If we obtain the line back-EMF constant $g(\theta)$ from 0 to 60 electrical degree by offline experiments, the electromagnetic torque in arbitrary rotor position can be calculated.

\section{Simulations and Experiments}

\subsection{Main parameters of motor}

A three-phase five pairs of brushless DC motor is used in simulation and experiment to verify the validity of the proposed DTC scheme. The rated voltage, rotational speed and power are $300 \mathrm{~V}, 3000 \mathrm{r} / \mathrm{min}$ and $400 \mathrm{~W}$, respectively;

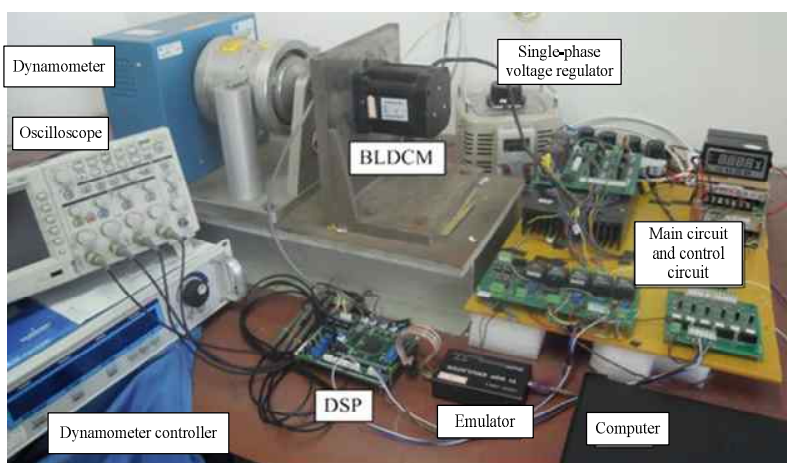

Fig. 5. DTC experimental system of BLDCM 
the winding resistance and inductance are $3.05 \Omega$ and $17 \mathrm{mH}$, respectively. The simulation was implemented by MATLAB/M-file where the sampling time is $25 \mu$ s. Fig. 5 shows the experimental system of direct torque control and DSP is TMS320F28335-150 from TI company. The sampling time is $25 \mu \mathrm{s}$ in torque control and current, the dclink voltage is $300 \mathrm{~V}$ and the load is dynamometer.

\subsection{Conventional direct torque control system}

Fig. 6 shows the experiment results for conventional direct torque control system in $500 \mathrm{r} / \mathrm{min}$ and $1.27 \mathrm{~N} . \mathrm{m}$ rated load. The phase inductance is $17 \mathrm{mH}, 300 \mathrm{~V}$ dc-link voltage, $25 \mu$ s torque control period, and 2-3 sampling delay, current ripple in the theory is above $0.2 \mathrm{~A}$, considering the obtained experimental results $(0.25 \mathrm{~A})$, the actual torque ripple reaches approximately to $30 \%$.

\subsection{Direct torque control system with hysteresis and PWM mode}

Fig. 7 shows the experiment results of direct torque control system with hysteresis and PWM mode in 500 $\mathrm{r} / \mathrm{min}$ and $1.27 \mathrm{~N} . \mathrm{m}$ rated load. In experiment, the four threshold $\left( \pm T_{t h 1}, \pm T_{t h 2}\right)$ of four-level hysteresis controller are \pm 0.03 and \pm 0.12 times of reference torque,

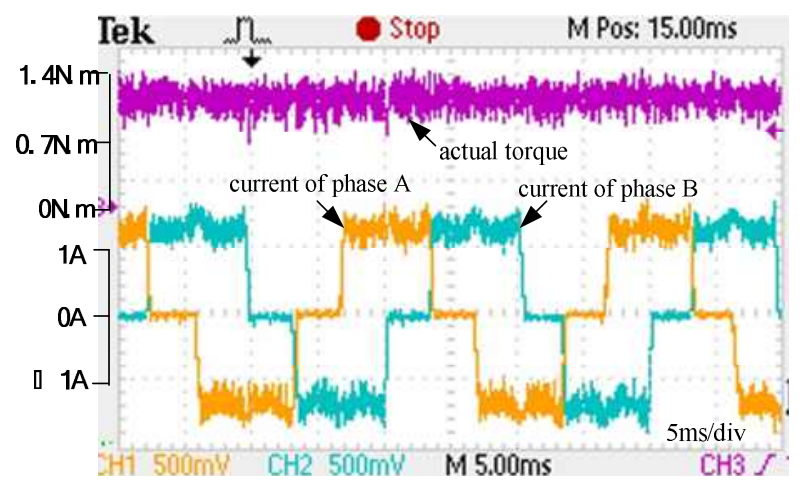

Fig. 6. Experimental result under conventional DTC system (rated load)

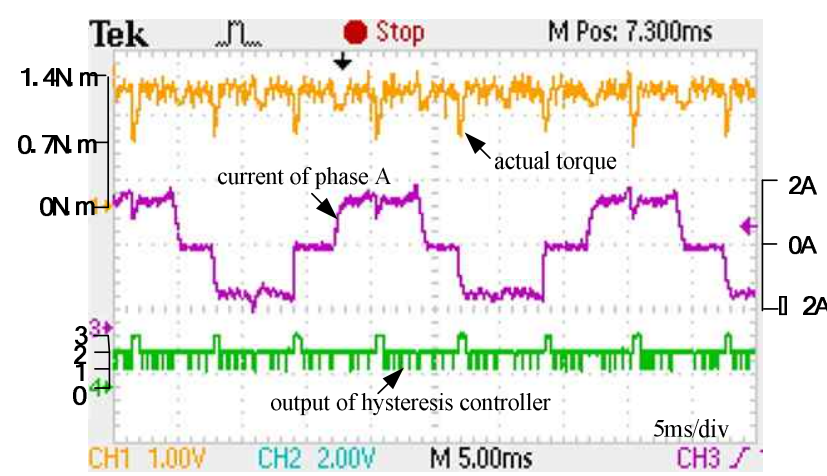

Fig. 7. Experimental result under DTC system with Hysteresis control and PWM mode(rated load) respectively. $D_{2}$ is considered as 0.5 times of operating speed. From the experiment results, large torque ripple in commutation appears every 120 electrical degree, which consistent with theory analysis.

\subsection{The proposed direct torque control system}

Figs. 8 and 9 show the simulation and experimental results of proposed DTC system in constant torque command considering rated load torque 1.27 N.m and speed in $500 \mathrm{r} / \mathrm{min}$ and $1000 \mathrm{r} / \mathrm{min}$, respectively.

From the experiment results, it can be seen that the torque ripple is controlled within about $12 \%$, and the simulation and experimental results are basically similar.

Figs. 10 and 11 show the simulation and experimental results of the proposed DTC system, when the torque command steps from negative rated to positive rated and come back to negative rated again where speed is considered as $500 \mathrm{r} / \mathrm{min}$ and $1000 \mathrm{r} / \mathrm{min}$, respectively. From

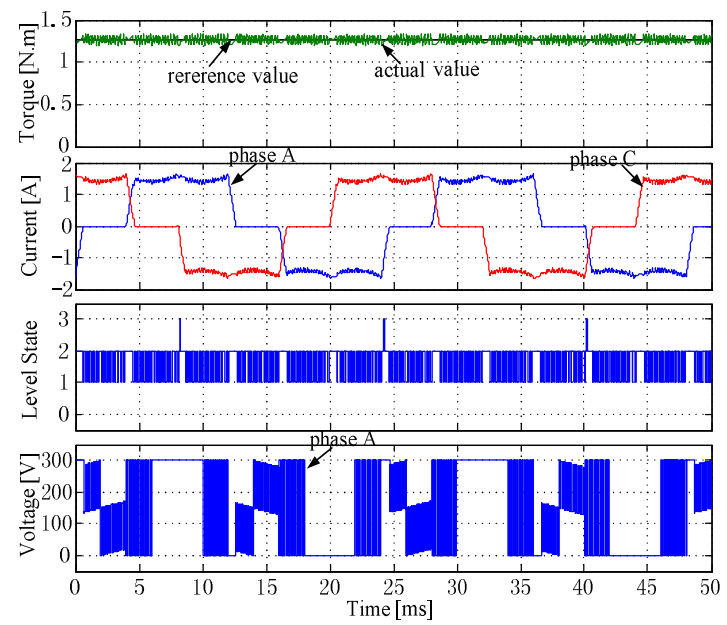

(a) $500 \mathrm{r} / \mathrm{min}$
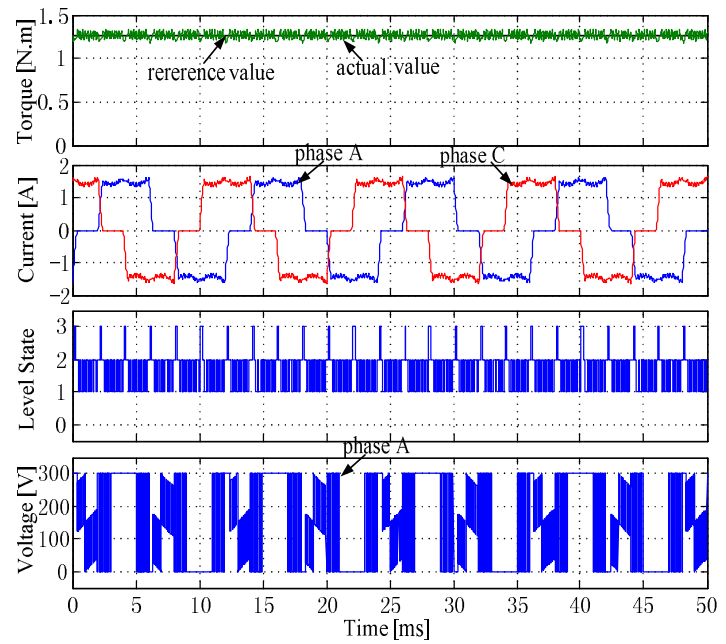

(b) $1000 \mathrm{r} / \mathrm{min}$

Fig. 8. Simulation result of proposed DTC system under constant torque reference(rated load) 


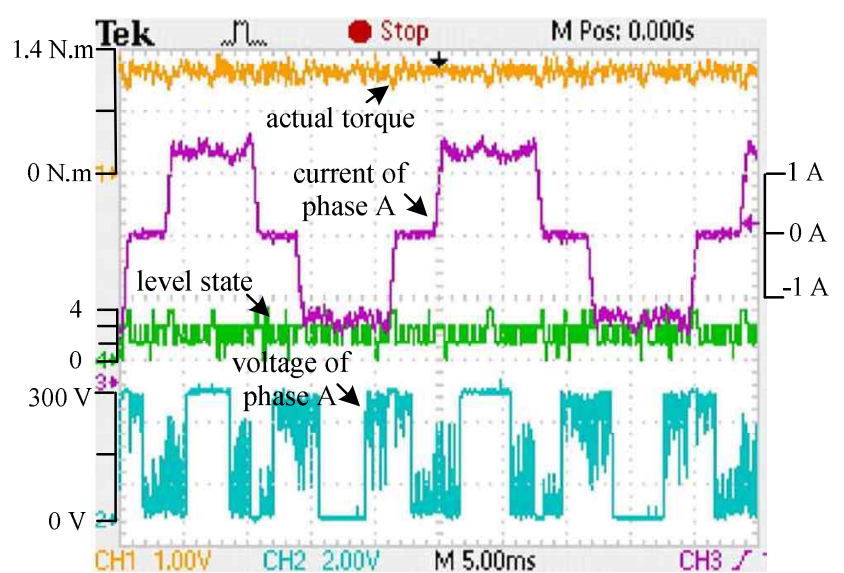

(a) $500 \mathrm{r} / \mathrm{min}$

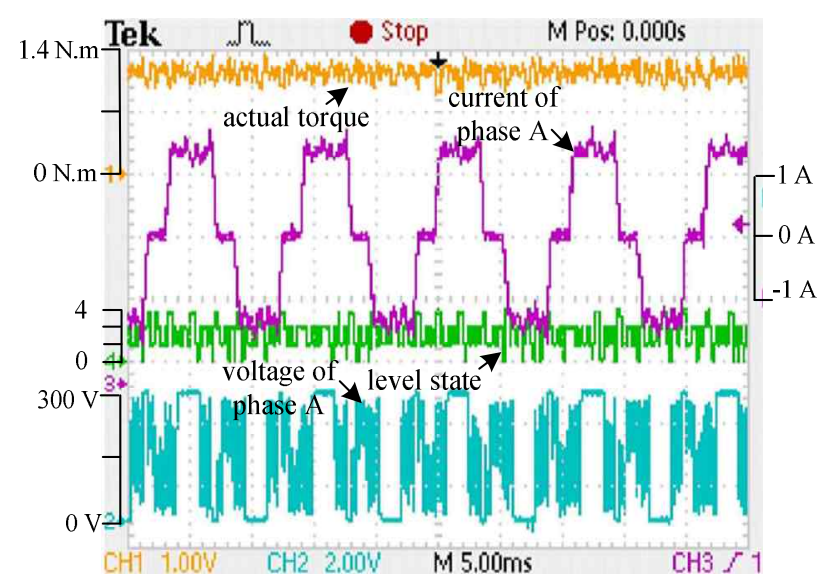

(b) $1000 \mathrm{r} / \mathrm{min}$

Fig. 9. Experimental result of proposed DTC system under constant torque reference(rated load)

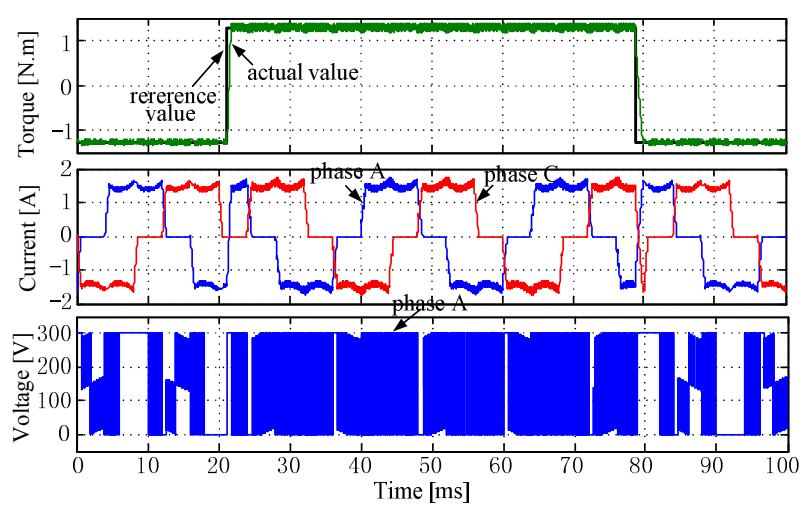

(a) $500 \mathrm{r} / \mathrm{min}$

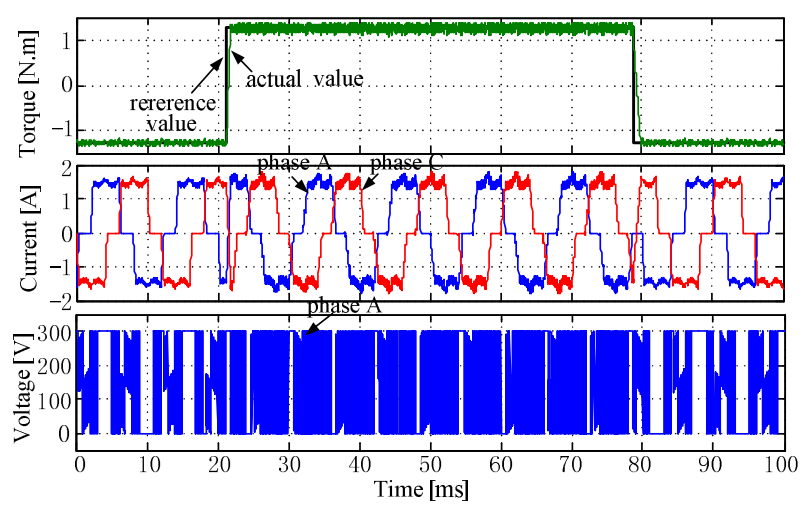

(b) $1000 \mathrm{r} / \mathrm{min}$

Fig. 10. Simulation result of proposed DTC system under step torque reference

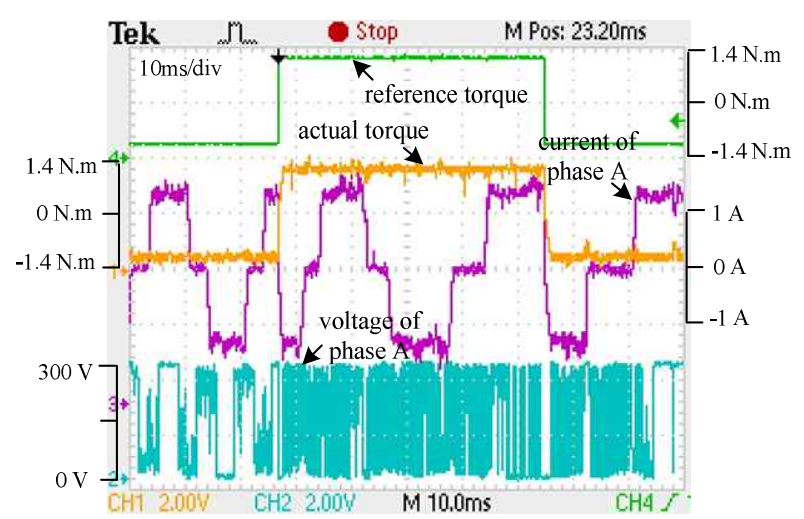

(a) $500 \mathrm{r} / \mathrm{min}$

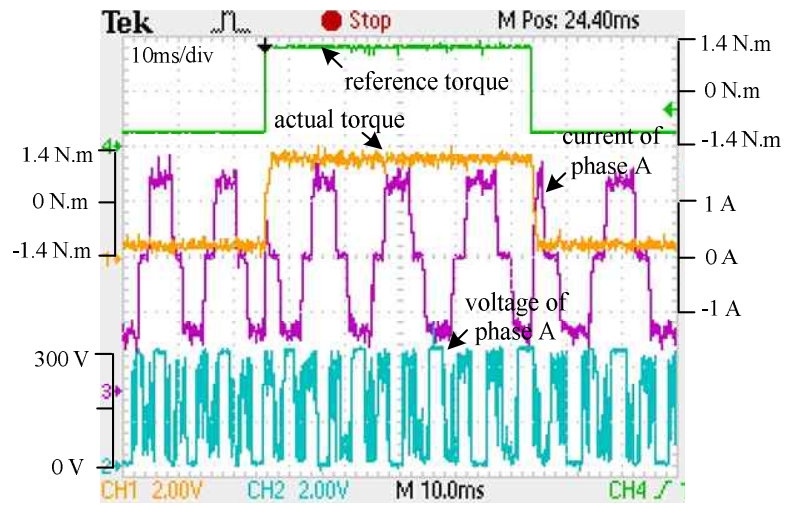

(b) $1000 \mathrm{r} / \mathrm{min}$

Fig. 11. Experimental result of proposed DTC system under step torque reference

simulation and experimental results, the actual torque tracks with reference torque well. This simulation focuses on torque dynamic performance, without considering effect of torque to rotational speed which results the displacement change is always the same in Fig. 10. In fact, as it can be seen from the experimental current waveform in Fig. 11, when the output torque changes from motoring mode to brake mode, the speed obviously get slow, until the output torque returns to motoring mode again.

Fig. 12 shows the experimental results of double closedloop control with half and full rated load, and motor starts up under reference of $1000 \mathrm{r} / \mathrm{min}$, after steady state 


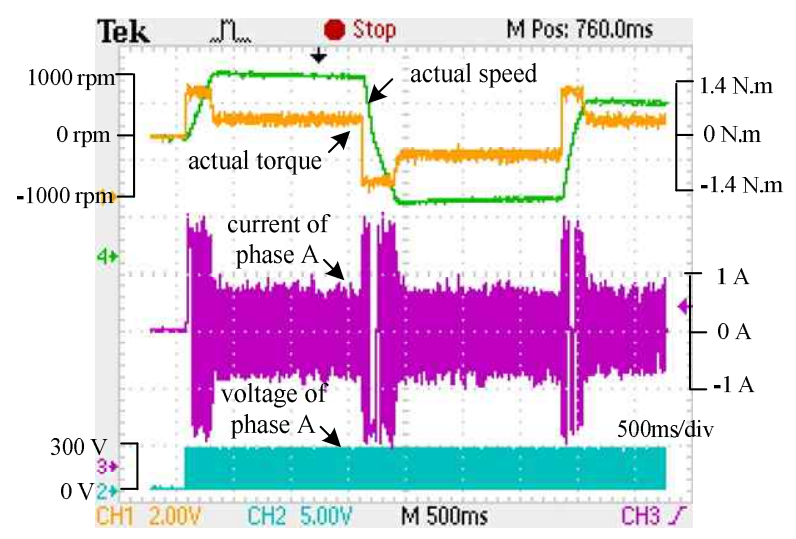

(a) half rated load

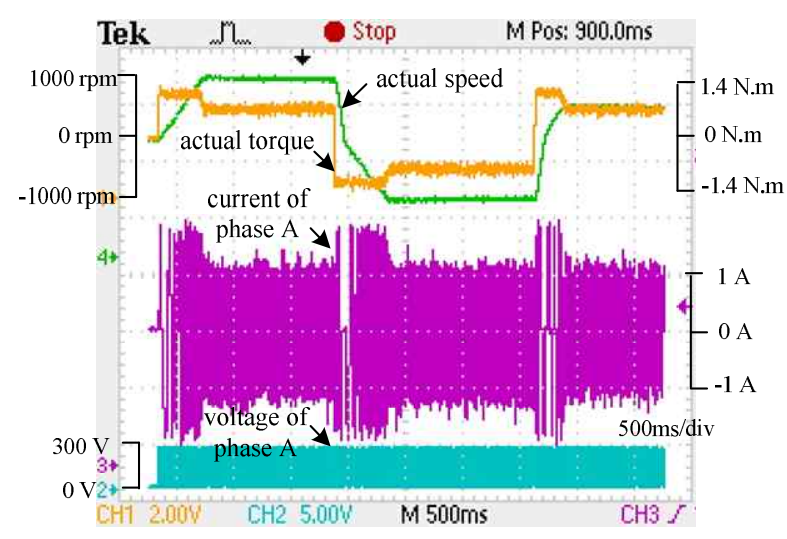

(b) whole rated load

Fig. 12. Experimental result of proposed DTC system under step speed reference

reference speed steps to $-1000 \mathrm{r} / \mathrm{min}$, then motor reversely rotates, at last reference speed steps to $500 \mathrm{r} / \mathrm{min}$. The experimental process contains four-quadrant operation. Motor starts up with maximum torque in the first quadrant, and operats in steady state. When the step reference speed is given $-1000 \mathrm{r} / \mathrm{min}$, motor reversely rotates in the third quadrant after transitional process in second quadrant. When the step reference speed is given $500 \mathrm{r} / \mathrm{min}$, motor forward rotates in the first quadrant after transitional process in fourth quadrant. From the experiment results, when the reference speed varies between positive and negative, speed changes more obviously in the second and fourth quadrant than the other quadrants. That is because output torque of the motor and load all play a brake effect at this time.

\section{Conclusion}

This paper proposed a direct torque control strategy for brushless DC motor to minimize torque ripple. The method combined hysteresis torque control and PWM mode, which avoided large current and torque ripple. At the same time, in the case when two-phase half-bridge $120^{\circ}$ conduction mode, improved lookup table of switching devices states solved torque ripple in commutation. Finally, simulation and experiment results were presented to verify the feasibility and effectiveness of the proposed strategy operating in four-quadrant operation.

\section{Acknowledgements}

This work was supported by the National Natural Science Foundation of China and Baosteel Group Co. Ltd. (Grant No.U1260203) and by the Natural Science Foundation-Steel and Iron Foundation of Hebei Province. (Grant No. F2013203291)

\section{References}

[1] Takashi Kenjo and Shigenobu Nagamori, "Brushless motors: advanced theory and modern applications," Tokyo, Japan: Sogo Electronics Press, 2003.

[2] Liu Yong, Zhu Z Q and Howe D, "Direct torque control of brushless DC drives with reduced torque ripple," IEEE Trans. On Industry Applications, vol. 41, no. 2, pp. 599-608, 2005.

[3] Liu Yong, Zhu Z Q and Howe D, "Commutationtorque-ripple minimization in direct-torque-controlled PM brushless DC drives," IEEE Trans. On Industry Applications, vol. 43, no. 4, pp. 1012-1021, 2007.

[4] Ozturk S.B., and Toliyat H.A, "Direct Torque and Indirect Flux Control of Brushless DC Motor," IEEE Trans. on Mechatonics, vol. 16, no. 2, pp. 351-360, 2011.

[5] Gao Jin and $\mathrm{Hu}$ Yuwen, "Direct self-control for BLDC motor drives based on three-dimensional coordinate system," IEEE Trans. on Industrial Electronics, vol. 57, no. 8, pp. 2836-2844, 2010.

[6] An Quntao, Sun Lizhi, Liu Chao and Sun Li, "Flux linkage self-control based direct torque control of brushless DC motor," Proceedings of the CSEE, vol. 30, no. 12, pp. 86-92, 2010.

[7] Seog-Joo Kang and Seung-Ki Sul, "Direct torque control of brushless DC motor with nonideal trapezoidal back EMF," IEEE Trans. on Power Electronics, vol. 10, no. 6, pp. 796-802, 1995.

[8] Zhenguo Li, Lu Wang, Songfa Zhang, Chunjiang Zhang, and Jin-Woo Ahn, "Torque Ripple Reduction in Direct Torque Controlled Brushless DC Motor," ICEMS2011, 2011. 


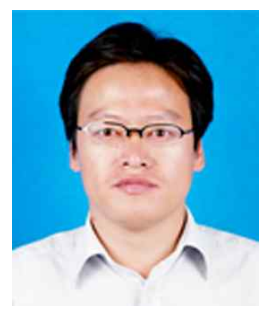

Zhenguo Li received the B.S. degree in electric machinery and electrical apparatus from Shenyang University of Technology, Shenyang, China, in 1994, and the M.S. and Ph.D. degrees in mechatronics engineering from Pukyong National University, Busan, Korea, in 2001 and 2005, respectively. $\mathrm{He}$ is currently with Yanshan University, Qinhuangdao, China, as an Associate Professor. His major research field is advanced electrical motor control.

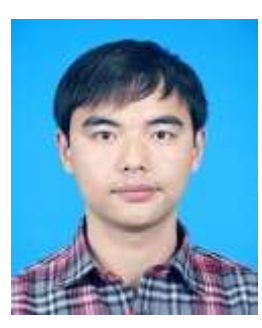

Songfa Zhang was born in Hubei, China in 1985. He received his B.S. and M.S. degree in Electrical Engineering from The City College of Jilin Jianzhu University, Changchun, China in 2009 and Yanshan University, Qinhuangdao, China in 2012, respectively. $\mathrm{He}$ is currently with Gree Electric Appliances, Inc, of Zhuhai, China, as a researcher. His major research field is advanced electrical motor control.

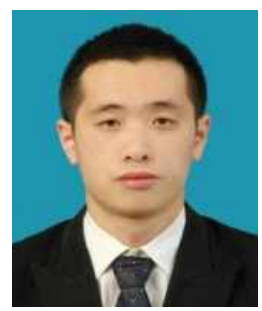

Shenghai Zhou was born in Heilongjiang, China in 1986. He received his B.S. and M.S. degree in Electrical Engineering from Southwest University for Nationalities, Chengdu, China in 2010 and Yanshan University, Qinhuangdao, China in 2013, respectively. Now he is working in State Grid Jibei Electric Power CO., LTD. Maintenance Branch. His research interests are Power Electronics and motor control system.

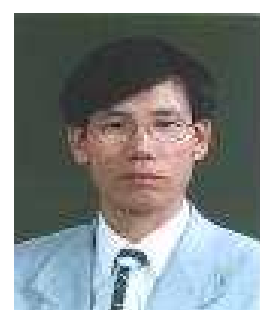

Jin-Woo Ahn He was born in Busan, Korea in 1958. He received his B.S., M.S., and Ph.D. degrees in Electrical Engineering from Pusan National University, Pusan, Korea in 1984, 1986, and 1992, respectively. He has been with Kyungsung University, Busan, Korea, as a professor in the Department of Mechatronics Engineering since 1992. He was a visiting researcher in the Speed Lab at Glasgow University, U.K., a visiting professor in the Dept. of ECE and WEMPEC at the University of Wisconsin-Madison, USA, and a visiting professor in the Dept. of ECE at Virginia Tech from July 2006-June 2007. He was the director of the Advance Electric Machinery and Power Electronics Center. $\mathrm{He}$ also has been the director of the Smart Mechatronics Advanced Research and Training Center from Aug. 2008 to July 2011 and the Senior Easy Life Regional Innovation
System since July 2008, President of Korea Regional Innovation System Association since December 2011 which are authorized by the Ministry of Knowledge Economy, Korea. He is the author of five books including SRM, the author of more than 150 papers and has more than 20 patents. His current research interests are advanced motor drive systems and electric vehicle drives. He has been the Editor-in-Chief of JICEMS. Dr. Ahn received several awards including the Best Paper Award from the Korean Institute of Electrical Engineers in 2002 and 2011, The Korean Federation of Science and Technology Society in 2003, Korean Institute of Power Electronics in 2007, Park Min-Ho Prize in 2009, Busan Science \& Technology Prize in 2011 and Ministerial Citation of Ministry of Knowledge Economy in 2011, respectively. He is a Fellow of the Korean Institute of Electrical Engineers, a member of the Korean Institute of Power Electronics and a senior member of the IEEE. 